\title{
Overview and Status of Korean-BPR
}

\author{
Yu-Jeong Choi and So-Young Lee*
}

Since the Korea Biocidal Products Regulation ${ }^{1}$ (also known as K-BPR) came into force on 1 January 2019, the Korean authorities have established an inventory of existing active biocidal substances, based on the notification of the substances by industry. Any company, who did notify the existing active substance - including its product type (PT) of use - was granted a grace period for substance approval. The biocide industry in South Korea is facing the first approval period which is due by the end of 2022 and potential registrants have little experience in dealing with biocide authorisations according to K-BPR. Compared to Korean-REACH ${ }^{2}(K-R E A C H)$, much higher data requirements are requested for $K-B P R$, which is basically a replication of the European Biocidal Product Regulation $(E U-B P R)^{3}$, encouraging registrants in global data sharing. This article outlines the procedures for active substance approval according to $K-B P R$, as the first significant tasks in the biocidal approval process in Korea.

\section{Introduction}

As a result of accidents associated with biocidal and consumer chemical products in South Korea, the KBPR was implemented to control these products as

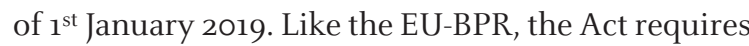
that all biocidal substances and products receive approval from the Ministry of Environment (MoE) prior to manufacture or import of those. Additionally, a company who notified an existing active substance and being granted a grace period for authorisation, can manufacture and import the existing active substance during this period without approval. In order to get the required authorisation of active substances under K-BPR, it is essential to understand the approving system, controlled by $\mathrm{MoE}$ and the defined processes, such as CICO (Chemical Substance Information Communicative Organization [similar to the SIEF under EU REACH]) formation, simplified approval, data sharing, etc. When the practical tasks

DOI: $10.21552 / \mathrm{icrl} / 2020 / 2 / 5$

* Yu-Jeong Choi is Project Manager of Consortia Asia. For Correspondence: <yj.choi@consortia-asia.com> So-Young Lee is Project Manager of Consortia Asia. For Correspondence: < sy.lee@consortia-asia.com>

1 Act on the Safety Management of Household Chemical Products and Biocides, Act No 15511, 20 March, 2018.

2 Act on the Registration and Evaluation of Chemical Substances, Act No 11789, 22 May, 2013.

3 Biocidal Products Regulation (Regulation (EU) No 528/2012). and assignments are identified and understood well, biocide registrants can progress the K-BPR approval procedures much more efficiently.It needs to be noted as well, that the current regulation and implementation procedures under K-BPR are constantly being updated, demanding to keep an eye on any update in order to respond appropriately.

\section{Active Substance Approval}

\section{Pre-Notification of Existing Active Substance}

In accordance with K-BPR, any person who intends to manufacture or import an active substance contained in biocidal product or a treated article placed on the Korean market before $31^{\text {st }}$ December 2018 (= existing active substance) is eligible to submit a notification of the existing active substance, including the product type (PT) claim. MoE reviewed the notified substances, incl. the product types and established on $31^{\text {st }}$ December 2019 the inventory of 741 existing active biocidal substances, which are subject to the grace period of the substance approval process. Since then, late notifications have been accepted and accordingly the inventory keeps updating on a regular base. As of today, 743 existing active substances are listed. 
Table 1: Grace period of existing active substance, depending on the PT.

\begin{tabular}{|c|c|}
\hline $\begin{array}{c}\text { Grace Period } \\
3 \text { years } \\
2022\end{array}$ & Product Type \\
\hline $\begin{array}{c}5 \text { years } \\
2024\end{array}$ & $\begin{array}{r}\text { Disinfectants, Algicide, Rodenticides, Insecticides, Repellents } \\
\text { Products to control other non-vertebrates }\end{array}$ \\
\hline $\begin{array}{c}8 \text { years } \\
2027\end{array}$ & $\begin{array}{r}\text { Preservative for products, Preservative product surface treatment, } \\
\text { Fibres and leather preservatives }\end{array}$ \\
\hline $\begin{array}{c}\text { 10 years } \\
2029\end{array}$ & $\begin{array}{r}\text { Construction material preservatives, Material/equipment preservatives, Embalming or } \\
\text { taxidermist fluids, Antifouling products }\end{array}$ \\
\hline
\end{tabular}

Depending on the notified product type (PT), the grace periods have been granted for up to 10 years. Table 1 shows the grace periods according to relevant product type. The grace periods provided did take into account additional information, such as volume, hazard, risk, use and global regulatory information of the existing active substances.

Any person who submitted a notification, shall submit a plan concerning the preparation of the substance approval to the MoE within one year from the designated date of existing active substance status. In case a company notified an active substance and accordingly the substance was included in the initial list of existing substances in 2019, the relevant approval plan should be submitted until the $31^{\text {st }}$ December 2020 . The plan should include a substance specific schedule for the substance approval. It should be separately submitted by any company who notified the existing active substance. In case that there are more than 2 companies who submit an approval plan for the same substance name and chemical composition, the companies should submit most of the approval dossier jointly via an agreed Lead Registrant.

\section{Active Substance Approval}

K-BPR approval of active substances requires data, which is more diverse and detailed comparing to $\mathrm{K}$ REACH. Moreover, the review process of the approval dossier submitted is complex and takes longer. The number of K-BPR studies required, such as physi- co-chemical properties and hazard data is 73 in total, whereas K-REACH requires 47 endpoints in comparison. Unlike K-REACH, which differentiates depending on the registration tonnage band, the requirements are identical for all manufactures and importers, regardless of the amount placed on the market. So, the volume of a biocide has no relevance concerning the required studies.

Thus, it might be quite burdensome on companies in terms of cost for data and approval process, in particular for low volume biocides placed on the Korean market. Accordingly, the Korean authority provides an easing of the requirements. A company who registered a substance under K-REACH does not need to submit the duplicate data for K-BPR approval. Also, simplified approval, which enables registrant to submit a reduced data set can be possible for selected substances, which have been previously approved internationally. Details of these reduced conditions can be found in Chapter 3 in this article. Table 2 shows the requirements of existing active substance notification and approval. The requirements of K-BPR are basically identical to the ones of EU-BPR.

Figure 1 describes the procedure scheme of the active substance approval and dossier review by the competent authority (CA). The official period required to receive approval decision by the CA takes up to 18 months at maximum. However, the period may be extended if the CA requests from the applicant to provide further information and to supplement the approval dossier. Accordingly, the applicant needs to set a tight plan for the active substance approval process considering the approval review peri- 
Table 2:Requirements of notification and active substance approval

\begin{tabular}{|c|l|}
\hline \multicolumn{1}{|c|}{ Obligation } & \multicolumn{1}{|c|}{ Requirements } \\
\hline Pre-notification & $\begin{array}{l}\text { Applicant information } \\
\text { Substance identification information } \\
\text { Product type } \\
\text { Annual manufacturing/importing volume } \\
\text { Global regulatory information }\end{array}$ \\
\hline \multirow{5}{*}{ Approval of active substance } & $\begin{array}{l}\text { Applicant Information } \\
\text { Identification information of active substance (analytical profile) } \\
\text { Exposure information (use, user, exposure route and behaviour) } \\
\text { Data on raw material and manufacturing process } \\
\text { Classification \& Labelling } \\
\text { Guidance on safe use } \\
\text { Global regulatory information } \\
\text { Physico-chemical and biological properties } \\
\text { Hazards to human and environment } \\
\text { Environmental fate and behaviour } \\
\text { Reactivity with packaging } \\
\text { Efficacy/Effectiveness } \\
\text { Risk assessment for human health and environment } \\
\text { Biocidal Assessment Report (BAR) }\end{array}$ \\
\hline
\end{tabular}

od. MoE recommends submitting approval documents within June 2021 at least for substances where the grace period expires end of 2022.

After the Lead Registrant (LR) submits the joint approval dossier to the CA, the CA will notify the LR on the initiation of the dossier evaluation and draft assessment report. Once the draft is drawn up by the $\mathrm{CA}$, the applicant will be allowed to view the draft and submit written comments during a period of 30 days. The applicant shall verify that the intention of the applicant has been delivered well and accordingly that the authority has assessed the active substance correctly, based on the properties of the substance. A Biocidal Committee will review the approval decision based on the final assessment report by the authority.

The completion of active substance approval will be followed by the biocidal product (BP) approval. Each company should submit the approval documents for the biocidal product, which includes the approved active substance. The approval grace period of each biocidal product is 2 years after the active substance has been approved. The approval proce-

4 Registration, Evaluation, Authorisation and Restriction of Chemicals (REACH) (Regulation (EU) No 1907/2006) dure for the biocidal product is very similar to the active substance approval.

Similar to EU-BPR, there is an expiration of approvals granted under the K-BPR. Approvals of active substances will be provided up to maximum of 10 years, considering hazards and risks of the active substance. For substances having a specific hazard, e.g. a respiratory sensitizer, the approval will be granted for a maximum of 7 years. Each registrant should re-new the active substance approval dossier before the expiration date.

\section{Data Sharing Under K-BPR}

The importance of global data sharing is increasing as chemical regulations are gradually expanding and developing into various jurisdictions. Looking at $\mathrm{REACH}^{4}$ and K-REACH representatively, basically all registrants of the same substance should belong to the joint registration. The registrants need to put priority on utilizing the existing data in order to reduce registration costs and time and avoid unnecessary testing, on vertebrate animals in particular. Moreover, ambiguous data could result in multiple testing, which needs to be prevented. Other chemicals legislations introduced worldwide also include the 


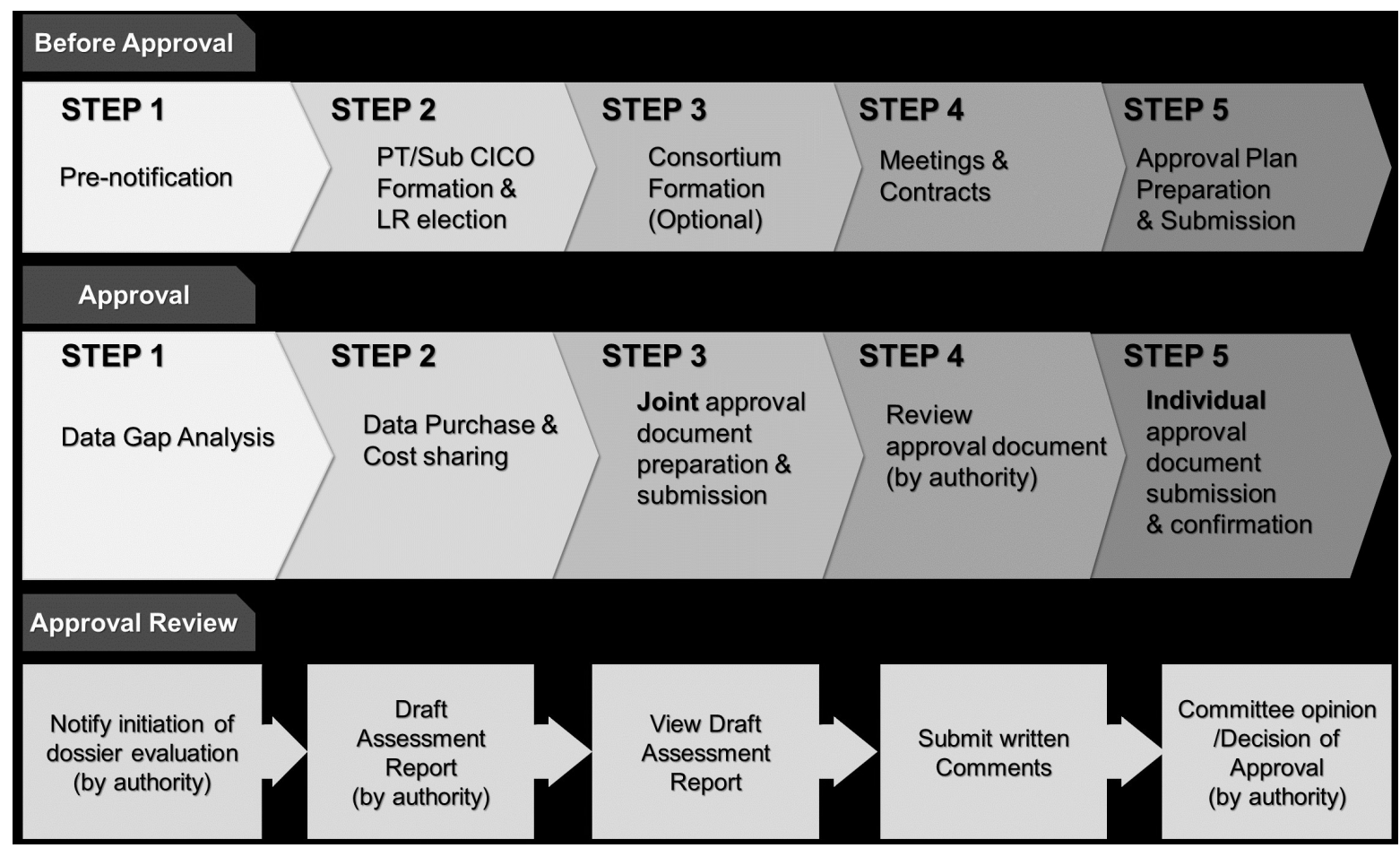

Figure 1: Scheme of the approval process for active biocidal substances

aspect of data sharing. The procedure of data exchange involving various stakeholders could be complex and especially require in-depth degree of understanding and administration, in order to meet the requirements of the relevant parties - while maintaining confidentiality.

\section{Exchange of Existing Data}

K-BPR requires the formation of CICOs by companies which manufacture or import the same active substance and to jointly submit the technical parts of the approval documents, such as physico-chemical properties, biological properties, and human and environment hazard data in accordance with the $\mathrm{K}$ BPR. In addition, vertebrate tests should be minimized and should not be repeated, except for special cases such as newly identified risks to humans or the environment. Since, the requirements are very similar to those from EU-BPR, data access to existing studies conducted under EU BPR should be utilized via Data Sharing Agreements. Global data sharing will link local registrants and data owners in other countries and offers the opportunity to continuous- ly cooperate with each other regulatory-wise, even after the K-BPR approval. It would therefore be important to find a common consensus among those, who aim to share data globally.

\section{Only Representative System}

The K-BPR amendment which will be in force on $1^{\text {st }}$ January 2021 has recently adopted the Only Representative system, alike the OR System under KREACH and EU REACH. Any non-Korean manufacturer will be able to proceed with the active substance and biocidal product approval, including the data sharing obligations, via their appointed Only Representative in South Korea.

\section{Operation of CICOs}

A registrant, who is required to submit joint approval dossier shall join the CICO in the web-based K-BPR system. The most basic unit of the CICO is the "Product Type CICO", which consists of registrants who notified the same biocidal product type for a sub- 
stance. Next, there is the substance CICO, representing several product type CICOs for the same substance. Basically, each lead registrant in product type CICOs is expected to be acting in the substance CI$\mathrm{CO}$ but any member in product type CICOs can act in the substance CICO as well. To avoid overlapping and redundant work and to prepare the approval dossier most efficiently, when preparing several product type dossiers for a substance, approval works need to be carried out by distributing the works between the lead registrants of a substance CICO and the product type CICOs, efficiently. In this regard, the substance CICO lead registrant, representing all CICO members, may overpeer the scientific study data and the preparation of core documents, which are required for all registrants of a substance, regardless of product types, e.g. Classification \& Labelling. In particular, the substance CICO lead registrant is expected to work closely with data owners, when securing existing data access. Moreover, since the current K-BPR let registrants form a separate CICO when registering anhydrous or hydrated forms of a substance, the importance of coordination work of the substance lead registrant is emphasized again. For example, each substance lead registrant needs to identify "the same" substance or group relevant substances correctly. Several substance CICOs may cooperate with each other. In this aspect, Consortium formation could be an efficient tool to avoid double work, to reduce expenses and to file a harmonised set of data during the K-BPR approval.

\section{Simplified Requirements}

MoE is carrying forward a plan to simplify the approval requirements of active substances which were authorised internationally. The MoE has announced that existing active substance for which a biocidal assessment was completed and assessment reports were published under the EU BPR and FIFRA ${ }^{5}$, will receive the opportunity to be exempted from the submission of certain hazard, risk, and efficacy data as well. The MoE will announce the final list of substances, for which data requirements will be reduced. Accordingly, MoE recently completed collating infor-

5 Federal Insecticide, Fungicide, and Rodenticide Act

6 Small and Medium-sized enterprises mation of substance and product, including raw material, use and exposure from the potential registrants who notified the existing active substances, which are the first to expire the approval grace period.

The registrants subject to the simplified requirements for K-BPR approval will hope to purchase the specific data which they really need, rather than being required to get access to the full data package for a substance.

Also, K-BPR allows not to submit duplicate data of a substance of which data already submitted to KREACH registration. Fair data sharing which identifies K-BPR registrant, who already paid for Letter of Access for K-REACH purpose and who did not, will be necessary.

According to the experience with K-REACH registrations, local Korean companies showed a tendency to prioritize cost efficiency. In this regard, there are CICOs who chose to replace test study requirements by waiving justification or public data rather than generate new test or purchase existing data. Also, many CICOs applied for the Korean authority's SMEs $^{6}$ supporting program, which produces demanding tests and provided test reports to K-REACH registrants at an affordable price. As it is expected that there would be similar cases in upcoming K-BPR approval, it would be important to consider these matters for data owners, who seeks to share data for $\mathrm{K}-\mathrm{BPR}$ purpose at a maximum price level.

\section{Conclusions}

In response to the chemical incidents and increasing awareness of risk from chemical substances, Korean authority started to control chemical substances broadly, e.g. through the K-REACH legislation, the new K-BPR legislation has been implemented to control biocidal and consumer products intensively. Recently subordinate statutes, relevant systems have been developing, and technical guidance has just been published regarding the K-BPR approval system.

Currently, the Tier 1 approval of existing active substances, ending by 2022, is closely coming. At the same time, the efforts for active substance approval from industry side seems low due to high costs as well as complex procedures. Especially, SMEs are facing major challenges in K-BPR compliance. To help the applicants for active substance and biocidal prod- 
uct approval, there is an urgent need of technical guidance, to prepare dossier in further detail. Also, securing the existing data at reasonable costs is a key to accelerate the whole process of approval. Korean chemical regulations have adopted many parts of European regulations, and there are benefits expected from the global data sharing in K-BPR implementa- tion as well. Nevertheless, there have been cases where CICOs turned down the offers from non-Korean data owners under K-REACH. Therefore, K-BPR applicants and (EU-BPR/EU REACH) data owners need to understand each side's stance in order to find agreement and that both sides are benefitting from the data sharing. 